\title{
The Effects of Cocaine Self-Administration on Dendritic Spine Density in the Rat Hippocampus Are Dependent on Genetic Background
}

\author{
Miguel Miguéns . Asta Kastanauskaite Santiago M. Coria , Abraham Selvas-, Inmaculada Ballesteros-Yañez , Javier DeFelipe and \\ Emilio Ambrosio
}

Abstract

Chronic exposure to cocaine induces modifications to neurons in the brain regions involved in addiction. Hence, we evaluated cocaine-induced changes in the hippocampal CA1 field in Fischer 344 (F344) and Lewis (LEW) rats, 2 strains that have been widely used to study genetic predisposition to drug addiction, by combining intracellular Lucifer yellow injection with confocal microscopy reconstruction of labeled neurons. Specifically, we examined the effects of cocaine self-administration on the structure, size, and branching complexity of the apical dendrites of CA1 pyramidal neurons. In addition, we quantified spine density in the collaterals of the apical dendritic arbors of these neurons. We found differences between these strains in several morphological parameters. For example, CA1 apical dendrites were more branched and complex in LEW than in F344 rats, while the spine density in the collateral dendrites of the apical dendritic arbors was greater in F344 rats. Interestingly, cocaine self-administration in LEW rats augmented the spine density, an effect that was not observed in the F344 strain. These results reveal significant structural differences in CA1 pyramidal cells between these strains and indicate that cocaine self-administration has a distinct effect on neuron morphology in the hippocampus of rats with different genetic backgrounds.

Key words CAl drugs of abuse Fischer 344 Lewis pyramidal neuron

Introduction

Chronic exposure to drugs of abuse induces a variety of persistent changes in behavior and brain morphology, including neuronal modifications in brain regions involved in addiction (Kalivas 2009; Russo et al. 2010; LaPlant and Nestler 2012). Studies analyzing the effects of drug administration on neuronal morphology have shown that contingent and noncontingent administration of cocaine, amphetamine, or morphine can alter morphological parameters like spine density, spine morphology, and dendritic branching of neocortical pyramidal and medium spiny accumbal neurons (Robinson and Kolb 2004; Ballesteros-Yanez, Ambrosio, et al. 2007; Ballesteros-Yanez, Valverde, et al. 2007; Ballesteros-Yanez et al. 2008; Shen et al. 2009; Singer et al. 2009; Dumitriu et al. 2011, 2012).

Although the hippocampus is not usually associated with addictive behaviors, it is thought to play a key role in contextual conditioning, and there is evidence that it plays a role in cocaine addiction (Koob and Volkow 2010). Moreover, addictive drugs may disrupt neurogenesis in the adult hippocampus (Canales 2007) and damage to the ventral subiculum of the hippocampus alters the acquisition of cocaine self-administration behavior in rats (Caine et al. 2001). Chronic cocaine administration modulates different forms of hippocampal plasticity, including long-term potentiation (LTP; Thompson et al. 2002, 2004; Del Olmo et al. 2006) and LTP depotentiation (Prakash et al. 2009; Miguens, Coria, et al. 2011). Furthermore, activation of the subiculum (the main output structure in the hippocampus) has been directly implicated in the reinstatement of cocaine seeking (Vorel et al. 2001), while inactivation of hippocampal output attenuates the cocaine seeking behavior elicited by associative cues and by cocaine injection (Sun and Rebec 2003; Rogers and See 2007).

Addiction is a complex disorder that results from the interaction of genetic and environmental factors. Genetic differences in susceptibility to drug addiction have been described in both animals and humans (Kosten and Ambrosio 2002; Uhl 2006), and the inbred Fischer 344 (F344) and Lewis (LEW) rat strains are widely used to study genetic predisposition to drug addiction (Kosten and Ambrosio 2002). We previously demonstrated that morphine self-administration induces changes in neuron morphology in different brain areas in LEW and F344 rats (Ballesteros-Yanez, Ambrosio, et al. 2007; Ballesteros-Yanez et al. 2008). Moreover, using the same self-administration regime as that used here, we found that cocaine self-administration alters LTP depotentiation in the hippocampus of LEW, but not F344 rats (Miguens, Coria, et al. 2011), suggesting that long-term cocaine exposure impairs the synaptic plasticity that supports learning. Interestingly, differences in hippocampal-dependent spatial learning have indeed been 
To determine whether these electrophysiological and behavioral indicators have neuromorphological correlates, we have investigated the effects of cocaine self-administration on different microanatomical parameters of CA1 hippocampal neurons in LEW and F344 rats. To this end, we performed single-cell microinjections of the fluorescent dye Lucifer yellow (LY) in fixed brain sections and subsequently, reconstructed the CA1 apical branches, quantifying spine density in the collateral dendrites of these neurons using confocal microscopy techniques.

Materials and Methods

\section{Animals}

Adult LEW $(n=12)$ and F344 ( $n=12)$ rats (Harlan Interfauna Ibérica, Barcelona, Spain) weighing 275-350 g were used in all the experiments. All the animals were experimentally naïve and they were housed individually in a temperature-controlled room $\left(23^{\circ} \mathrm{C}\right)$ on a 12-h light/dark cycle (lights on 08:00-20:00), with ad libitum access to Purina laboratory feed (Panlab, Barcelona, Spain) and tap water prior to beginning experiments (unless otherwise specified). All experiments were carried out in accordance with the European Communities Council Directive of 24 November 1986 (86/609/EEC), and all efforts were made to minimize the number of animals used and their suffering.

\section{Surgery}

Rats were anesthetized with ketamine $(40 \mathrm{mg} / \mathrm{kg})$ and diazepam $(10 \mathrm{mg} / \mathrm{kg})$, and a polyvinylchloride tube $(0.064$ i.d.) was surgically implanted into the jugular vein approximately at the level of the atrium, as described previously (Miguens, Botreau et al. 2013). The catheter was passed subcutaneously to exit in the midscapular region, and it was then passed through a spring tether system (Alice King, Chatham, USA) that was mounted to the skull of the rat with dental cement. All subjects were housed individually following surgery and they were given at least 7 days to recover. To prevent infection and maintain catheter patency, the catheters were flushed daily with $0.3 \mathrm{~mL}$ of an antibiotic solution (gentamicin, $0.10 \mathrm{mg} / \mathrm{mL}$ ) dissolved in heparinized saline. At the end of each experiment, the catheter patency was also tested by infusing the barbiturate anesthetic thiopental $(10 \mathrm{mg} / \mathrm{kg}$, i.v.), and the catheter was assumed to be unblocked if the rat immediately lost consciousness.

\section{Experimental Procedure}

Cocaine Self-Administration

Twelve operant chambers (Coulburn Instruments, Allentown, PA, USA) were used for the cocaine self-administration studies. Active lever presses resulted in drug delivery, while inactive lever presses were recorded but had no consequences. Before surgery, LEW and F344 rats were food-deprived until they reached 95\% of their free-feeding weight, and they were then placed on a fixed ratio (FR)- 1 schedule of food reinforcement for several 30 min sessions. When rats showed a stable rate of lever pressing, they were allowed ad libitum access to food and surgery was performed. After a postoperative recovery period of at least 7 days, the rats were food-deprived again until they reached $95 \%$ of their free-feeding body weight. Subsequently, they were trained to self-administer cocaine $(1 \mathrm{mg} / \mathrm{kg}$ per $100 \mu \mathrm{L}$ infusion; LEW and F344, $n=6$ per strain) or saline (LEW and F344, $n=6$ per strain) for at least 20 days on a FR-1 schedule of reinforcement with a timeout period of $10 \mathrm{~s}$. Daily training sessions lasted for $2 \mathrm{~h}$ or until the rats earned 20 cocaine infusions. In response to a lever press, a microliter injection pump (Harvard 22; Harvard Apparatus) was used to deliver the cocaine or saline infusions over $10 \mathrm{~s}$.

\section{Intracellular Injections}

Twenty-four hours after the last self-administration session, rats were perfused intracardially with $4 \%$ paraformaldehyde in $0.1 \mathrm{M}$ phos phate buffer (PB, pH 7.4) and their brains were removed to perform the intracellular injections of LY. The brains were postfixed for $24 \mathrm{~h}$ in $4 \%$ paraformaldehyde in PB, and coronal vibratome sections were obtained (200 $\mu \mathrm{m}$ : Lancer 1000; St Louis, MO, USA). Cell injections were performed as described previously (Elston and Rosa 1997; Benavides-Piccione et al. 2005), in brief, sections were prelabeled with 4,6-diamidino-2-phenylindole (DAPI, D9542; Sigma, St Louis, MO, USA) and a continuous current was used to inject cells with the fluorescent dye LY [8\% in $0.1 \mathrm{M}$ Tris buffer $(\mathrm{pH} 7.4)]$. At least $15 \mathrm{CA} 1$ pyramidal cells per animal (Fig. 1A) were injected individually with LY, applying the current until the distal tips of each dendrite fluoresced brightly. To visualize the morphology of the cells, after injection the sections were incubated with a rabbit antibody against LY produced at the Cajal Institute [diluted 1:400 000 in stock solution: 2\% bovine serum albumin (A3425; Sigma), 1\% Triton X-100 (30632; BDH Chemicals, Poole, UK), and 5\% sucrose in $\mathrm{PB}]$, and subsequently with an Alexa 488-conjugated goat antirabbit secondary antibody $(1: 1000$; Invitrogen, Carlsbad, CA, USA).

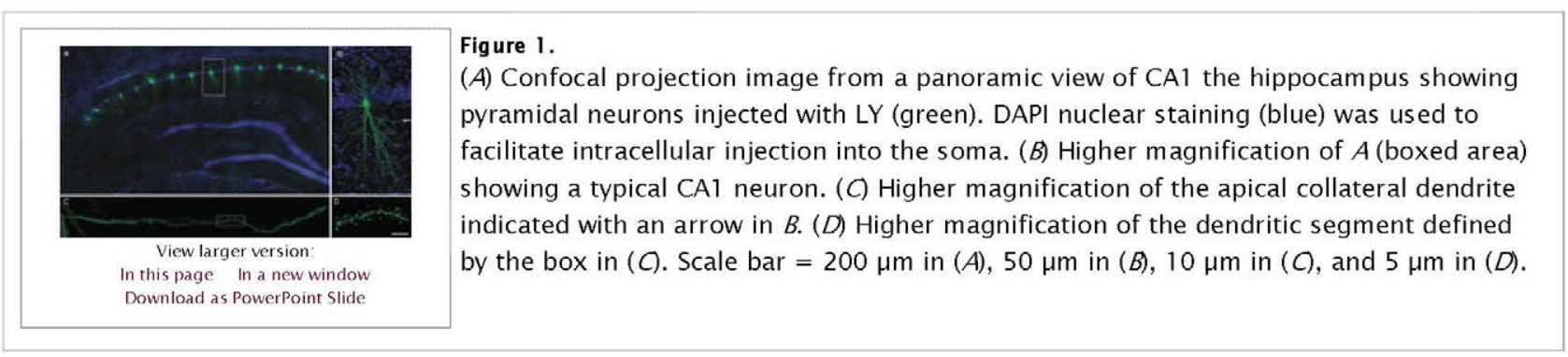

Cell Reconstruction and Morphometric Analysis

For apical dendrite reconstruction, 3-dimensional (3D) z-stacks were acquired with a Zeiss confocal microscope (LSM 710, Carl Zeiss Microlmaging $\mathrm{GmbH}$, Germany) using a $\times 20$ objective lens (voxel size, $0.415 \times 0.415 \times 1.00 \mu \mathrm{m}^{3}$ ). We selected $6-8$ apical dendrites per animal. In addition, using the same microscope with a $\times 63$ oil objective, we obtained 3D $z$-stacks (voxel size, $0.057 \times 0.057 \times$ $0.14 \mu \mathrm{m}^{3}$ ) of at least 6 collateral dendrites per animal from the apical shaft to the end of the distal tip. These images were deconvoluted using the Autodeblur software (MediaCybernetics, Inc., Bethesda, MD, USA). Tridimensional reconstruction of the 
Stack module of Neurolucida (MicroBrightField, Inc., Vermont, USA). This module opens an image stack of confocal images and allows the measurement of several morphological parameters of dendritic arborization and spine density.

To assess apical arborization complexity, we selected at least 6 main apical branches that were visible along the entire radiatum layer and reached the stratum lacunosum (Fig. 1B). The following parameters were analyzed:

1. (1) Dendritic field area - the area of a neuron's dendritic field calculated as the area enclosed by a polygon created by joining the most distal points of the dendritic processes (the 2D convex Hull area).

2. (2) Dendritic volume (surface area of 3D convex Hull).

3. (3) Total dendritic length and the total number of nodes and dendritic endings.

4. (4) Branching complexity (Sholl analysis)-dendritic length and the number of dendritic intersections, nodes, and endings within concentric $10 \mu \mathrm{m}$ radial spheres, calculated as a function of distance from the soma.

Spine Density in the Collateral Dendrites of CA1 Pyramidal Cells

The dendritic spine density on collateral dendrites of labeled cells was determined by counting the number of spines from the shaft of the apical dendrite to the distal tips of at least 6 random dendrites per animal (Fig. 1C,D). The dendrites selected were located between 30 and $120 \mu \mathrm{m}$ from the pyramidal layer and they fluoresced uniformly from the shaft of the apical dendrite to the distal-most part of the tip. Spine density was calculated by dividing the total number of spines per dendrite by the total dendritic length. A Sholl analysis was also performed in concentric $10 \mu \mathrm{m}$ radial spheres, and the results were expressed in function of the distance from the shaft of the apical dendrite.

\section{Statistical Analysis}

Differences between groups that self-administered cocaine or saline were analyzed using a mixed analysis of variance (ANOVA) with the between-subject factors "treatment" (cocaine or saline) and "strain" (LEW or F344), and the within-subject factor "session." The total number of injections and average number of injections per session in each group were analyzed using a 2-way ANOVA, with strain and treatment as independent variables. The morphometric parameters of the apical dendrite (total length, volume, and area) and spine density were analyzed using a 2-way ANOVA, with strain and treatment as independent variables. The Sholl analysis of spine density was performed using a mixed ANOVA with the between-subject factors treatment (cocaine or saline) and strain (LEW or F344), and the within-subject factor distance-to-apical dendrite shaft. A 2-way ANOVA followed by Student's $t$-test was used where appropriate. All statistical analyses were performed using the SPSS statistical package (version 19.0).

Results

\section{Cocaine Self-Administration}

The number of self-administered infusions of saline or cocaine per session by LEW and F344 rats on a FR-1 schedule of reinforcement is shown in Figure $2 A$, and the total cocaine intake is depicted in Figure $2 B$. Repeated-measures ANOVA revealed a significant session $\times$ strain $\times$ treatment interaction $\left(F_{19,380}=2.40 ; P<0.001\right)$, and the rats of both strains that self-administered cocaine self-administered more infusions than those that received saline $\left(f_{1,20}=63.46 ; P<0.0001\right)$. While a repeated-measures ANOVA revealed the number of cocaine infusions across sessions to be significantly higher in $\mathrm{F} 344$ than in LEW rats $\left(F_{1} 9,190=2.94\right.$; $P<0.001$ ), no significant differences in total cocaine consumption were observed between the strains (LEW, $221.8 \pm 26.05 \mathrm{mg} / \mathrm{kg}$; F344, $242.2 \pm 28.22 \mathrm{mg} / \mathrm{kg} ; t(10)=0.53, P=0.61)$.

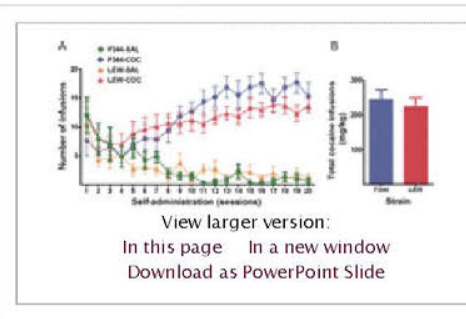

Figure 2 .

Cocaine self-administration behavior of F344 and LEW rats. $(A)$ Average number of infusions per session. Blue circles (F334, $n=6$ ) and red triangles (LEW, $n=6$ ) represent the number of cocaine infusions during the self-administration sessions. Green circles (F344, $n=6$ ) and orange triangles (LEW, $n=6$ ) correspond to saline animals in the same conditions. Cocaine self-administering animals showed more robust responses than those that self-administered saline. (B) Bars represent the total cocaine intake in both strains after 20 days of self-administration. No differences in total cocaine intake were observed between LEW and F344 rats.

Reconstruction and Morphometric Analyses of CA1 Pyramidal Apical Dendrites

ANOVA revealed a significant main effect of strain on the total number of endings $\left(f_{1,20}=53.3 ; P<0.001\right)$, intersections $\left(f_{1,20}=\right.$ $32.8 ; P<0.001)$, and nodes $\left(F_{1,20}=56.0 ; P<0.001\right)$, as well as on dendrite length $\left(F_{1,20}=25.0 ; P<0.05\right)$. All of these parameters were higher in CA1 pyramidal neurons from LEW rats than those from F344 rats (Fig. 3; see Supplementary Table 1). However, we observed no statistically significant differences between these strains for either the dendritic field area or dendritic volume.

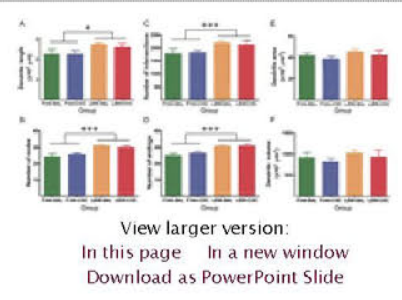

Download as PowerPoint Slide

\section{Figure 3.}

Branch morphology of pyramidal CA1 apical dendrites. The figure shows the different morphological parameters analyzed: $(A)$ Total dendritic length; $(B)$ number of dendritic nodes; $(C)$ number of intersections; $(D)$ number of endings; $(E)$ dendritic area; and $(F)$ dendritic volume. Dendritic length and the number of dendritic nodes, endings, and intersections in CA1 pyramidal neurons were higher in LEW than in F344 rats. No differences in either dendritic field area or dendritic volume were observed between strains. Cocaine self-administration had no effect on any of the branch complexity-

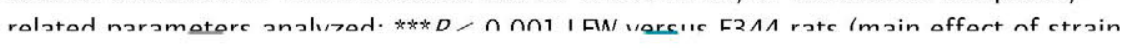


No significant effect of cocaine self-administration was observed on any of the morphological parameters in either LEW or F344 rats. Indeed, a Sholl analysis of dendritic length and the number of dendritic nodes, intersections, and endings revealed no effect of the strain $\times$ treatment $\times$ distance interaction (Fig. 4; see Supplementary Tables 2-5). For representative drawings of the apical dendrites in each condition see Figure 5 .

\begin{tabular}{|l|l|}
\hline Figure 4. \\
Branch complexity of pyramidal CA1 apical dendrites (Sholl analysis). Graphs \\
representing the different morphological parameters analyzed in the apical dendrites of \\
CA1 pyramidal neurons calculated in function of the distance from the soma within the \\
same concentric $10 \mu \mathrm{m}$ radial spheres: Dendritic length $(A)$ and the number of \\
intersections $(B)$, nodes $(C)$, and endings $(D)$. The data represent the mean \pm SEM in \\
function of the distance from the shaft of the apical dendrite. Neither strain differences \\
nor cocaine-induced effects were observed.
\end{tabular}

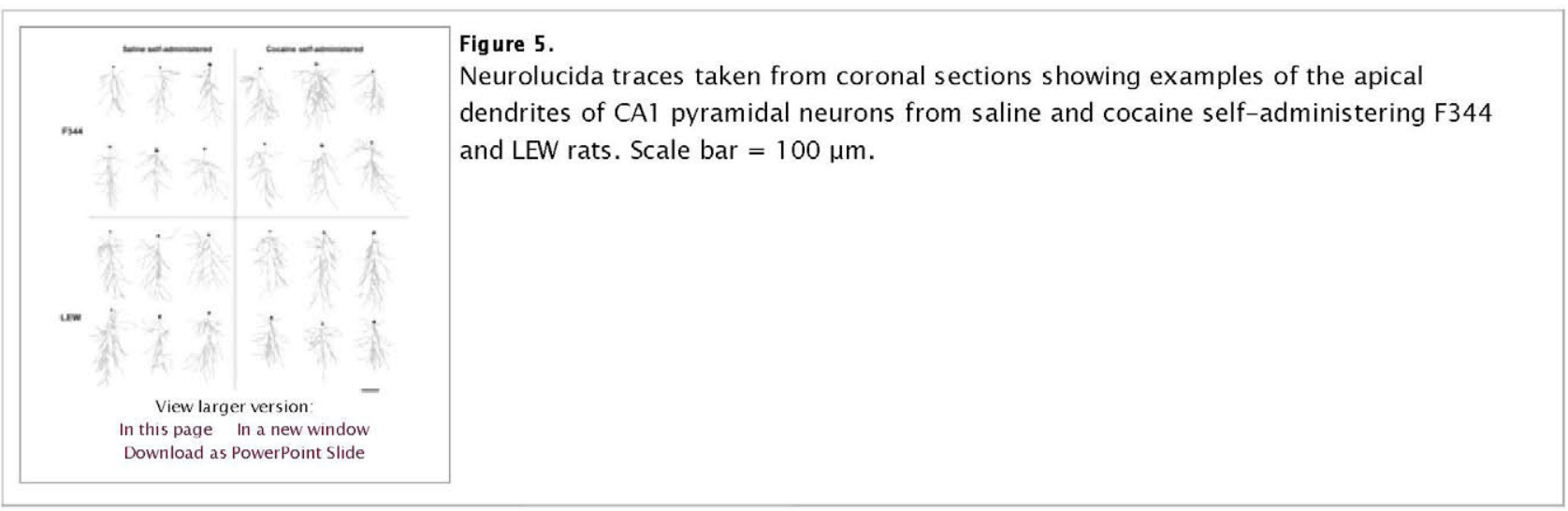

\section{Spine Density Analysis of the Collateral Dendrites of CA1 Pyramidal Neurons}

When the spine density on the collateral dendrites of the apical arbors of CA1 pyramidal neurons in F 344 and LEW rats that self-administered saline or cocaine was assessed (Fig. $6 A$; see Supplementary Table 6 ), ANOVA revealed a significant strain $\times$ treatment interaction $\left(f_{1,20}=8,55 ; P<0.01\right)$. Cocaine self-administration increased the spine density in LEW, but not in F344 rats, whereas LEW rats that self-administered saline exhibited a significantly lower spine density than their F344 counterparts. Indeed, a Sholl analysis revealed a significant strain $\times$ treatment interaction $(f 1,20=7.82 ; P=0.01)$. Spine density was greater in LEW rats that self-administered cocaine than in those that self-administered saline, with significant differences observed at 50,60 , and $90 \mu \mathrm{m}$ from the shaft of the apical dendrite (Fig. $6 B$; see Supplementary Table 7). In contrast, cocaine self-administration had no effect on spine density in F344 rats. Representative dendrites in each condition are shown in Figure 7.

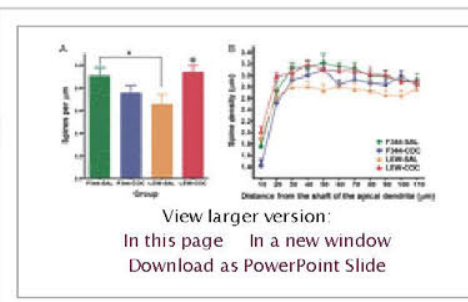

Figure 6.

Spine density in the collateral dendrites of pyramidal CA1 cells. Spine density on the collateral dendrites of CA1 hippocampal neurons was higher in F344 than in LEW rats. In addition, cocaine self-administration increased the spine density in LEW, but not in F344 rats $(A)$. In LEW rats, the differences in spine density were observed at 50,60 , and $90 \mu \mathrm{m}$ from the shaft of the apical dendrite $(B)$. The data represent the mean \pm SEM in function of the distance from the shaft of the apical dendrite: ${ }^{*} P<0.05$ with respect to LEW-saline; $+P<0.05$ with respect to $\mathrm{F} 344$-saline; $n=6$ per group.

Figure 7.

Projections of high-resolution 3D confocal stacks after deconvolution to illustrate the representative dendritic spine density for each group (A). Higher magnification image of the dendritic segment over the boxed area in $A(B)$. Scale bar: $10 \mu \mathrm{m}$ in $(A) ; 2 \mu \mathrm{m}$ in (B). 


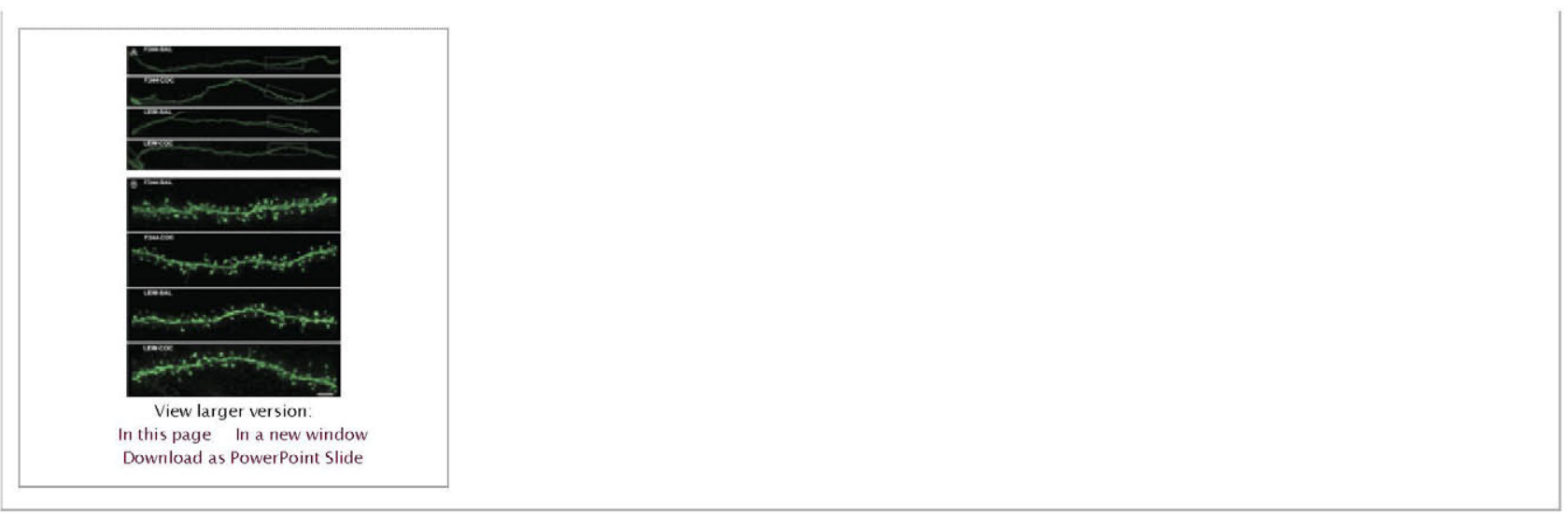

Discussion

In the present study, we demonstrate that genetic background influences how cocaine self-administration affects spine density on the collaterals of apical dendrites from rat CA1 pyramidal cells. Cocaine self-administration increased spine density in LEW, but not in F344 rats. Moreover, we observed significant strain differences in terms of spine density and the structure of the apical dendrites, whereby CA1 apical dendrites were more branched and complex in LEW rats, although their spine density was lower than that of F344 rats. The morphological differences found in dendritic arborization in these 2 strains of rats may have important functional consequences. Indeed, pyramidal cells are the most abundant neurons in the cerebral cortex (estimated to represent $70-80 \%$ of the total neuronal population), where they are the main source of excitatory (glutamatergic) synapses. The dendritic spines on pyramidal cells are the main postsynaptic target of excitatory synapses in the cerebral cortex and thus, pyramidal cells are considered the principal building blocks of this structure (reviewed in DeFelipe and Farinas 1992; Freund and Buzsaki 1996). Larger dendritic arbors imply a wider topographic sampling of the region, and it has been suggested that a more complex branching pattern may determine the degree to which the integrations of inputs are compartmentalized within their arbors, with this greater potential for compartmentalization resulting in a significant increase in the representational power (reviewed in Elston 2007). All or almost all dendritic spines establish at least one excitatory glutamatergic synapse (e.g., Arellano et al. 2007) and therefore, differences in the number of spines in the dendritic arbors of neurons may influence both cellular and system cortical functions. The differences in the length, number of branches, and spine density affect the electrical, biochemical, and biophysical properties of the synaptic inputs of the pyramidal neuron (reviewed in Elston 2007; Spruston 2008; Yuste 2010), and variations in these parameters reflect differences in the complexity and information processing that are likely to have important implications for learning and memory. Thus, the differences observed in the morphology of the CA1 pyramidal neurons between these 2 rat strains may be related, at least in part, to their differential behavioral sensitivity to psychoactive drugs.

Cocaine Affects the Spine Density of CA1 Pyramidal Neu rons

Chronic cocaine administration increases spine density in several areas of the brain, including the hippocampus (Robinson and Kolb 1999; Ballesteros-Yanez, Valverde, et al. 2007; Russo et al. 2010; Fole et al. 2011; Dumitriu et al. 2012). As stated in the Introduction, individual genetic differences have been proposed to underlie the differential effects of some drugs in the brain (Kosten and Ambrosio 2002; Uhl 2006). Indeed, we observed an increase in spine density after cocaine self-administration in LEW, but not in F344 rats. This increase in hippocampal spine density in LEW rats may be related to the hippocampal deregulation reported following cocaine self-administration. It is noteworthy that psychomotor stimulants, including cocaine, have been proposed to severely impair processes related to adult neurogenesis in the hippocampus (see Canales 2013). Moreover, lesion of the ventral subiculum of the hippocampus moderately impairs cocaine self-administration in rats (Caine et al. 2001). We previously showed that cocaine self-administration produces a downregulation of glutamate transporters (Miguens et al. 2008) and significant alterations in the cannabinoid system (Rivera et al. 2013) in the hippocampus, including the CA1 field. Moreover, cocaine self-administration has been shown to facilitate LTP potentiation (Thompson et al. 2005; Del Olmo et al. 2006) and to impair LTP depotentiation (Miguens, Coria, et al. 2011) in the hippocampus. Increases in spine density in hippocampal neurons after cocaine administration were also observed in F344 rats (Fole et al. 2011), but cocaine was passively administered and augmented spine density was observed after several learning trials in a radial maze. Given the lack of a control group with cocaine alone, an interaction between learning and cocaine administration in the abovementioned study should not be ruled out.

There is evidence from several studies that cocaine administration causes deficits in hippocampal-dependent learning and memory (Melnick et al. 2001; Quirk et al. 2001; Santucci et al. 2004; Bashkatova et al. 2005). In contrast, post-training cocaine administration facilitates the consolidation of spatial memory (Iniguez et al. 2012), and cocaine self-administration enhances the performance of LEW rats in the Morris water maze (Del Olmo et al. 2007). However, elsewhere chronic i.p. cocaine administration did not affect the performance of either LEW or F344 rats in the radial arm maze (Fole et al. 2011). Taken together, these results suggest that the effect of cocaine treatment on learning depends on several factors, including the type of task analyzed and the form of administration (contingent or noncontingent). The effects of cocaine on learning and memory appear to be complex, in some cases resulting in memory deficits and in others memory facilitation or learning consolidation.

Differences in Dendrite Morphology and Spine Density of CA1 Pyramidal Neurons in LEW Versus F344 Rats We observed significant strain differences in the arborization and spine density of CA1 apical dendrites. In LEW rats, CA1 apical dendrites were more branched and complex, although they had less spine density than their F344 counterparts, as reported before (Fole et al. 2011). We previously described morphological differences between these strains in other brain areas, including the motor and prelimbic cortices in which dendrites were longer in LEW versus F344 rats (Ballesteros-Yanez et al. 2008). Interestingly, the 
spine density but shorter dendrites and fewer dendritic nodes, endings, and intersections than their LEW counterparts. Based on these observations, it is tempting to speculate that the lower values observed for the various morphology parameters of neurons in F344 rats may be compensated by the increased spine density in these animals. These differences may represent an anatomical substrate responsible for the deficits in hippocampal-dependent tasks (van der Staay et al. 2009; Fole et al. 2011), and could be related to the impaired LTP depotentiation reported in F344 rats (Prakash et al. 2009; Miguens, Coria, et al. 2011).

Defective dendrite morphology and deficits in spine density during development have been linked to abnormal cortical wiring in several neurological disorders, including mental retardation, autism, and schizophrenia (Broadbelt et al. 2002; Benavides-Piccione et al. 2004; Hutsler and Zhang 2010). Decreased dendritic arborization is associated with mental retardation in murine models of Down syndrome (Benavides-Piccione et al. 2004), and increased dendritic spine density on cortical projection neurons has been reported in autism spectrum disorders (Hutsler and Zhang 2010). Dysfunctional play, lower social interactions, a reduced startle response, and greater prepulse inhibition have also been described in F344 when compared with LEW, Wistar, and Buffalo rats (Siviy et al. 1997, 2003 , 2011). Moreover, the CA1 pyramidal neurons of F344 rats are more vulnerable to ischemic insult than those of SpragueDawley and Wistar rats (Iwasaki et al. 1995). Thus, the neurobiological and behavioral characteristics of F344 rats suggest that this strain exhibits several features associated with different neurological disorders.

Differences in spine density between LEW and F344 rats are not restricted to the hippocampus. We previously described reduced spine density in the prelimbic cortex of F344 versus LEW rats, whereas no such differences were observed in the motor cortex (Ballesteros-Yanez et al. 2008). Therefore, strain differences in spine density vary according to the brain area, which serves to highlight the differences between circuits mediating distinct aspects of behavior. In response to environmental enrichment, the dendritic branching of cortical neurons in different areas and layers is altered, with different effects in the apical and basal fields (Gelfo et al. 2009). The reduced dendritic arborization observed in F344 compared with LEW rats could be related to the differences observed in the acquisition of cocaine self-administration, as these animals took longer to acquire this behavior (Kosten et al. 1997; Kosten et al. 2007). In contrast, the effects that cocaine exposure has on spine density in the LEW, but not in the F344 strain may contribute to the higher sensitivity to cocaine in LEW rats that was demonstrated by others with extended access programs (Picetti et al. 2010). It has been suggested that the hippocampus exerts a modulatory influence on reward processing due to its connections in the nucleus accumbens (Mittleman et al. 1990; Schmelzeis and Mittleman 1996). Moreover, reduced expression of the cannabinoid receptor type $1(\mathrm{CB} 1)$ receptor and fatty acid amide hydrolase $(\mathrm{FAAH})$, and activation of endocannabinoid signaling pathways in the hippocampus, contribute to the pronounced differences in reward sensitivity between F344 and Wistar rats (Brand et al. 2012). Interestingly, we previously described lower FAAH immunoreactivity in the stratum radiatum of the hippocampus in F344 versus LEW rats (Rivera et al. 2013). Furthermore, the basal dendritic arbor of pyramidal cells in the motor cortex of CB1 knockout mice is smaller and contains fewer dendritic spines than that of their wild-type littermates (Ballesteros-Yanez, Valverde, et al. 2007). These findings demonstrate that the contribution of the endocannabinoid system to the differences in spine density described in the present study should not be ruled out.

It is well known that LEW and F344 strains differ in a number of neurobiological parameters, both at the behavioral and molecular levels (Kosten and Ambrosio 2002). Thus, genetic factors may contribute to the behavioral, physiological, and morphological differences between these strains at the level of CA1 hippocampal pyramidal neurons, and their differential susceptibility to cocaine. The present study represents a further step toward the characterization of cocaine effects on the CA1 of the hippocampus, but it would be useful to build upon this by studying additional brain regions that are particularly relevant to drug addiction. These differences in hippocampal pyramidal cell morphology between strains may have an impact on learning and memory processes, and in neurological disorders, as previously reported. Our results suggest that cocaine addiction alters the morphology of neurons in the CA1 field of the hippocampus, leading to learning and memory deficits. Taken together, these findings indicate that individual genetic differences appear to be underlie the susceptibility to develop addiction-like disorders.

Supplementary material

Supplementary material can be found at: http://www.cercor.oxfordjournals.org/.

Funding

This work was supported by grants from the following entities: the Spanish Ministry of Health, Social Services and Equality (grant PND-20121057 to E.A.), the Carlos III Health Institute (grant RD12/0028/0020 to E.A.), the UNED Plan for the Promotion of Research (grant 2010V/PUNED/0005 to M.M.), the Centre for Networked Biomedical Research into Neurodegenerative Diseases (CIBERNED, CB06/05/0066 to J.DF.), and the Spanish Ministry of Economy and Competitiveness (grant BFU2012-34963 to J.DF). Cocaine clorhydrate was kindly provided by the "General Directorate of Narcotics" (Spain).

Notes

The authors thank Rosa Ferrado and Isabel Fernaud Espinosa for technical assistance. Conflict of Interest. None declared.

(c) The Author 2013. Published by Oxford University Press. All rights resenved.For Permissions, please e-mail: journals.permissions@oup.com

References

Arollann II Feninnca A Fairon A Vucto R DeFelipe J. Non-synaptic dendritic spines in neocortex. Neuroscience 2007; 145:464-469.

doi:10.1016/j.neuroscience.2006.12.015.

CrossRef Medline Web of Science

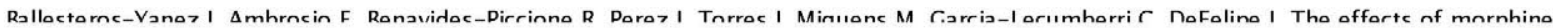

self-administration on rortical nuramidal cell structure in addirtion-nrone lewis rats Cereh Cortex $2007 \cdot 17 \cdot 738-749$ doi:10 1093/rerror/hhil4) 


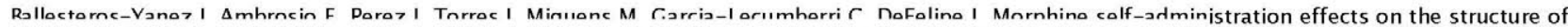
cortical pyramidal cells in addiction-resistant rats. Brain Res 2008;1230:61-72. doi:10.1016/j.brainres.2008.06.128.

CrossRef Medline web of Science

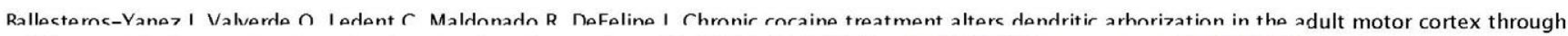
a CB1 cannabinoid receptor-dependent mechanism. Neuroscience 2007;146:1536-1545. doi:10.1016/j.neuroscience.2007.03.017.

CrossRef Medline Web of Science

Rachkatnia V Mauniar I Maurira T Vanin A Mamnn immairmants and oxidative stress in the hippocampus of in-utero cocaine-exposed rats. Neuroreport 2005;16:1217-1221. doi:10.1097/00001756-200508010-00017.

CrossRef Medline Web of Science

Ranavidac_Pirrinne R Arollann II noFolino I rator.holaminergic innervation of pyramidal neurons in the human temporal cortex. Cereb Cortex 2005;15:1584-1591. doi:10.1093/cercor/bhi036.

Abstract/FREE Full Text

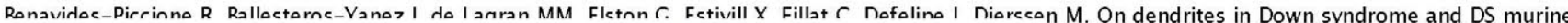
models: a spiny way to learn. Prog Neurobiol 2004;74:111-126. doi:10.1016/j.pneurobio.2004.08.001.

CrossRef Medline Web of Science

Rrand T Snanaral R Srhnoidor M norroscod roward concitivity in rate from the Ficrhor2 44 strain compared to Wistar rats is paralleled by differences in endocannabinoid signaling. PLoS One 2012;7:e31169. doi:10.1371/journal.pone.0031169.

CrossRef Medline

Rrnadhalt K Ryno W Innoc IR Fvidenro for a derreaco in basilar dendrites of pyramidal cells in schizophrenic medial prefrontal cortex. Schizophr Res 2002;58:75-81. doi:10.1016/S0920-9964(02)00201-3.

CrossRef Medline Web of Science

Caino SR Humbu T Rnhhinc TW/ Fvaritt RI Rohavinal offorte of nevehnmetor ctimulante in ratc with dnreal nrvontral cuhirulum lesions: locomotion, cocaine self-administration, and prepulse inhibition of startle. Behav Neurosci 2001;115:880-894. doi:10.1037/0735-7044.115.4.880.

CrossRef Medline Web of Science

Canales JJ. Deficient plasticity in the hippocampus and the spiral of addiction: focus on adult neurogenesis. Curr Top Behav Neurosci $2013 ; 15: 293-312$. Medline Google Scholar

Canales JJ. Adult neurogenesis and the memories of drug addiction. Eur Arch Psychiatry Clin Neurosci 2007;257:261-270. doi:10.1007/s00406-007-0730-6. CrossRef Medline Web of Science

nofoline I Farinac I The muramidal noumn of the rorahral cortex: morphological and chemical characteristics of the synaptic inputs. Prog Neurobiol

1992;39:563-607. doi:10.1016/0301-0082(92)90015-7.

CrossRef Medline Web of Science

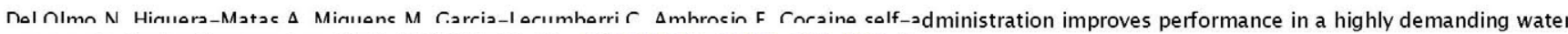
maze task. Psychopharmacology (Berl) 2007;195:19-25. doi:10.1007/s00213-007-0873-1.

CrossRef Medline

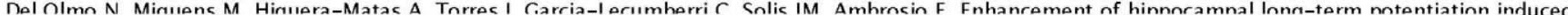
by cocaine self-administration is maintained during the extinction of this behavior. Brain Res 2006;1116:120-126. doi:10.1016/j.brainres.2006.07.001

CrossRef Medline Web of Science

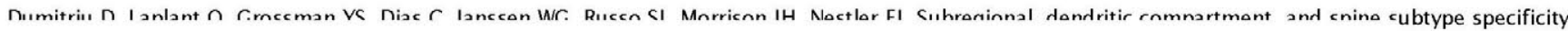
in cocaine regulation of dendritic spines in the nucleus accumbens. J Neurosci 2012;32:6957-6966. doi:10.1523/JNEUROSCI.5718-11.2012. Abstract/FREE Full Text

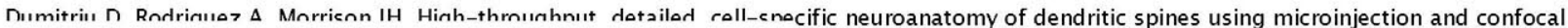
microscopy. Nat Protoc 2011;6:1391-1411. doi:10.1038/nprot.2011.389.

CrossRef Medline

Fletnn C.N Snorializatinne in m/ramidal cell structure during primate evolution. In: Kaas JH, Preuss TM, editors. Evolution of nervous systems. Oxford: Academic Press; 2007. p. 141-242.

Google Scholar

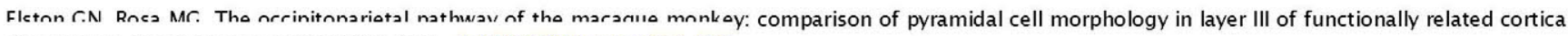
visual areas. Cereb Cortex 1997;7:432-452. doi:10.1093/cercor/7.5.432.

Abstract/FREE Full Text

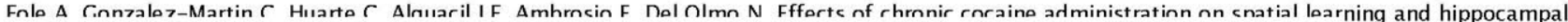
spine density in two genetically different strains of rats. Neurobiol Learn Mem 2011;95:491-497. doi:10.1016/j.nlm.2011.02.012.

CrossRef Medlıne

Fround TF Rurcaki G. Interneurons of the hippocampus. Hippocampus 1996;6:347-470. doi:10.1002/(SICI) 1098-1063(1996)6:4<347::AID-

$\mathrm{HIPOI}>3.0 . \mathrm{CO} ; 2-\mathrm{I}$.

CrossRef Medline web of Science

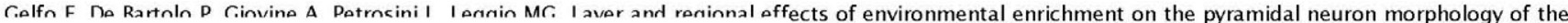
rat. Neurobiol Learn Mem 2009;91:353-365. doi:10.1016/j.nlm.2009.01.010.

CrossRef Medline Web of Science

Hutclar II 7hane H Inrrascad dandritic spine densities on cortical projection neurons in autism spectrum disorders. Brain Res 2010;1309:83-94.

doi:10.1016/j.brainres.2009.09.120.

CrossRef Medline Web of Science 
C57BL/6 mice. Hippocampus 2012;22:802-813. doi:10.1002/hipo.20941.

CrossRef Medline Web of Science

huscaki H nhmarhi $\vee$ Kurme E, Krieglstein J. Strain differences in vulnerability of hippocampal neurons to transient cerebral ischaemia in the rat. Int J Exp

Pathol 1995;76:171-178.

Medline web of Science Google Scholar

Kalivas PW. The glutamate homeostasis hypothesis of addiction. Nat Rev Neurosci 2009;10:561-572. doi:10.1038/nrn2515.

CrossRef Medline Web of Science

Koob GF, Volkow ND. Neurocircuitry of addiction. Neuropsychopharmacology 2010;35:217-238. doi:10.1038/npp.2009.110.

CrossRef Medline Web of Science

Kncton TA $\Delta$ mhrncin F HPA avic function and drur addirtiva hahavinre incishte from studies with Lewis and Fischer 344 inbred rats.

Psychoneuroendocrinology 2002;27:35-69. doi:10.1016/S0306-4530(01)00035-X.

CrossRef Medline Web of Science

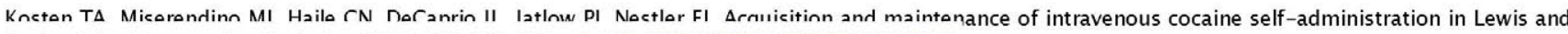
Fischer inbred rat strains. Brain Res 1997;778:418-429. doi:10.1016/S0006-8993(97)01205-5.

CrossRef Medline Web of Science

Kncton TA Thana XV Hailo $C \mathrm{~N}$ Ctrain difforonroc in maintonanro of cocaine self-administration and their relationship to novelty activity responses. Behav Neurosci 2007;121:380-388. doi:10.1037/0735-7044.121.2.380.

CrossRef Medline Web of Science

I aplant $\cap$ Nectlor FI CRArKinn the histone code: cocaine's effects on chromatin structure and function. Horm Behav 2012;59:321-330.

doi:10.1016/j.yhbeh.2010.05.015.

Web of Science

Molnirk SM Kuhio II I I Innani R חnw-FAwardc nI Imnairmont of spatial learning following preweaning cocaine exposure in the adult rat. Neurotoxicol Teratol 2001;23:445-451. doi:10.1016/S0892-0362(01)00157-X

CrossRef Medline Web of Science

Miruóne M Rntraau F nlíac $O$ Mol Olmn N Coria SM Hirusra-Matas A Amhrnsin F renotir differences in the modulation of accumbal glutamate and $\gamma$-amino butyric acid levels after cocaine-induced reinstatement. Addict Biol 2013;18:623-632.

CrossRef Medline Google Scholar

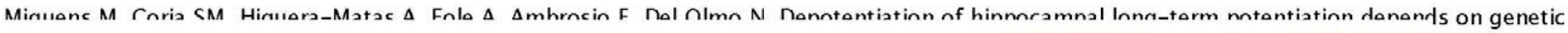

background and is modulated by cocaine self-administration. Neuroscience 2011;187:36-42. doi:10.1016/j. neuroscience.2011.04.056.

CrossRef Medline Web of Science

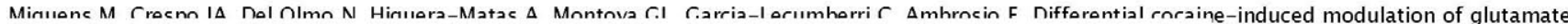
and dnnamine tranennotere sftor rontinnent and non-contingent administration. Neuropharmacology 2008;55:771-779.

doi:10.1016/j.neuropharm.2008.06.042.

CrossRef Medline Web of Science

Mittloman C. Whichaw In Innos C.H Korh M Rnhhinc TW. Cortical, hippocampal, and striatal mediation of schedule-induced behaviors. Behav Neurosci 1990;104:399-409. doi:10.1037/0735-7044.104.3.399.

CrossRef Medline Web of Science

Dirotti R Hn $\Delta$ Rutalman FR Krook MI nnco nroforonro and dnco ocralatinn in ovtonded-access cocaine self-administration in Fischer and Lewis rats. Psychopharmacology (Berl) 2010;211:313-323. doi:10.1007/s00213-010-1899-3.

CrossRef Medline

Prakach \& Amhrncin F Alruaril IF nol Olmo N. Genetic differences in hippocampal synaptic plasticity. Neuroscience 2009;161:342-346.

doi:10.1016/j.neuroscience.2009.03.061.

CrossRef Medline Web of Science

nıirk DI Rirharde RIN $\Delta$ van $\mathrm{n}$ C Cuhrhmnir ronraina nrndıces training paradigm-dependent learning deficits in laboratory rats. Pharmacol Biochem Behav 2001;68:545-553. doi:10.1016/S0091-3057(01)00462-2.

CrossRef Medline

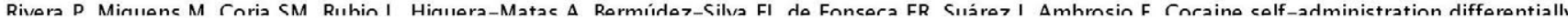
mndilatos the sxnrossion of endogenous cannabinoid system-related proteins in the hippocampus of Lewis vs. Fischer 344 rats. Int J Neuropsychopharmacol 2013;16:1377-1393.

Google Scholar

Rohinenn TF Kolh R Altoratinne in the mornholnav of dandritoc and dendritir eninoc in the nurlouc arrumbene and nrofrontal cortex following repeated treatment with amphetamine or cocaine. Eur J Neurosci 1999;11:1598-1604. doi:10.1046/j.1460-9568.1999.00576.x.

CrossRef Medline Web of Science

Rnhincon TF Kolh R Strurtural nlactiritv associated with exposure to drugs of abuse. Neuropharmacology 2004;47(Suppl 1):33-46

doi:10.1016/j.neuropharm.2004.06.025.

CrossRef Medline Web of Science

Rnnorc II Soe RF Solortive inartivation of the vontral hinnnramnuc attonuates cue-induced and cocaine-primed reinstatement of drug-seeking in rats. Neurobiol Learn Mem 2007;87:688-692. doi:10.1016/j.nlm.2007.01.003.

CrossRef Medline

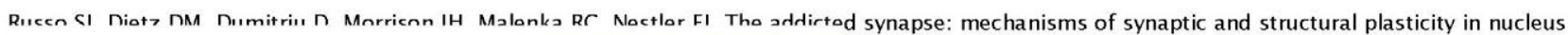
accumbens. Trends Neurosci 2010;33:267-276. doi:10.1016/j.tins.2010.02.002.

CrossRef Medline Web of Science 
reversible with time. Neurotoxicol Teratol 2004;26:651-661. doi:10.1016/j.ntt.2004.06.002.

CrossRef Medline Web of Science

Srhmolsaic Mr Mittloman $\mathrm{S}$. Tho hinnnramnuc and roward effects of hippocampal lesions on progressive-ratio responding. Behav Neurosci

1996;110:1049-1066. doi:10.1037/0735-7044.110.5.1049.

CrossRef Medline Web of Science

Shan HW Tnda S Mnıссаwi k Rnuknirht A, Zahm DS, Kalivas PW. Altered dendritic spine plasticity in cocaine-withdrawn rats. J Neurosci 2009;29:2876-2884. doi:10.1523/JNEUROSCI.5638-08.2009.

Abstract/FREE Full Text

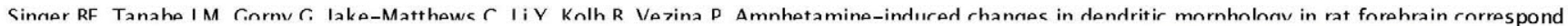
to associative drug conditioning rather than nonassociative drug sensitization. Biol Psychiatry 2009;65:835-840. doi:10.1016/j.biopsych.2008.12.020. CrossRef Medline Web of Science

Siriv, SM Ralikn CN Rnumarc KC Rnursh-and-tumble play behavior in Fischer-344 and buffalo rats: effects of social isolation. Physiol Behav 1997;61:597-602. doi:10.1016/S0031-9384(96)00509-4.

CrossRef Medline Web of Science

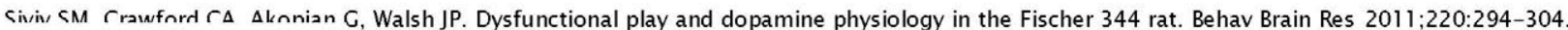

doi: $10.1016 /$ j.bbr.2011.02.009.

CrossRef Medline Web of Science

Civiv, CM I nvo NI norirrn RM Cinrranno SB, Seifert TL. The relative playfulness of juvenile Lewis and Fischer-344 rats. Physiol Behav 2003;80:385-394. doi:10.1016/j.physbeh.2003.09.002.

CrossRef Medline Web of Science

Spruston N. Pyramidal neurons: dendritic structure and synaptic integration. Nat Rev Neurosci 2008;9:206-221. doi:10.1038/nrn2286.

CrossRef Medline Web of Science

Sun W, Rebec GV. Lidocaine inactivation of ventral subiculum attenuates cocaine-seeking behavior in rats. J Neurosci 2003;23:10258-10264. Abstract/FREE Full Text

Thnmmonn AM Cincnell RA Warner II Fnhanroment of Innr-term potentiation in the rat hippocampus following cocaine exposure. Neuropharmacology 2002;42:1039-1042. doi:10.1016/S0028-3908(02)00059-X.

CrossRef Medline Web of Science

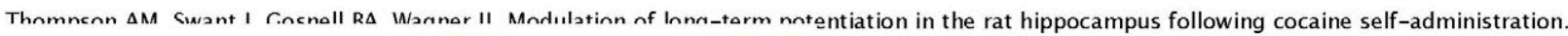

Neuroscience 2004;127:177-185. doi:10.1016/j.neuroscience.2004.05.001.

CrossRef Medline Web of Science

Thnmmenn $\Delta M A$ Siwant I W/arner II Cnraine-indured mndulation of long-term potentiation in the CAl region of rat hippocampus. Neuropharmacology 2005;49:185-194. doi:10.1016/j.neuropharm.2005.03.005.

CrossRef Medline Web of Science

CUhl GR. Molecular genetics of addiction vulnerability. NeuroRx 2006;3:295-301. doi:10.1016/j.nurx.2006.05.006. Copyright (c) 2014 Oxford University Press CrossRef Medline

Site Man Privacv Policv Cookie Policv leaal Notices Freauentlv Asked Ouestions van der Staav FI Srhumirman T van Resnon Cr. Korte SM Fmotinnal raartivity and cognitive performance in aversively motivated tasks: a comparison between four rat strains. Behav Brain Funct 2009;5:50. doi:10.1186/1744-9081-5-50. CrossRef Medline

Vnral SR I in X Havac RI Snartor JA, Gardner EL. Relapse to cocaine-seeking after hippocampal theta burst stimulation. Science 2001;292:1175-1178. doi:10.1126/science. 1058043 .

Abstract/FREE Full Text

Yuste R. Dendritic spines. Cambridge, MA: MIT Press; 2010.

Google Scholar 